\title{
Synthesis and Characterization of New Fused Heterocyclic Compounds Consisting of Benzodiazepine, Quinoxaline, Benzimidazole and Thiazole Rings
}

\section{Lecturer Dr. Nadia Adil Salih*,Assistant Lecturer Hanan Abd El-Latif Ibraheem*}

\begin{abstract}
Date of acceptance 2/4/2008

In this study, new heterocyclic compounds were synthesized through the cyclization reactions of $o$-phenylenediamine (1) with various organic reagents. Benzodiazepine derivatives (24) were obtained by reaction of (1) with ethylacetoacetate, malonic acid and acetyl acetone.Treatment of compound (1) with chloroacetamide, chloroacetic acid, p-bromophenacyl bromide and oxalic acid dihydrate afforded quinoxaline derivatives (5-8), respectively. Reaction of compound (1) with benzoic acid, piperonal, cyclohexanone and carbon disulfide resulted in the formation of compounds (9-12), respectively. Finally, reaction of compound (12) with chloroacetic acid in the presence of potassium hydroxide produced compound (13).
\end{abstract}

Keywords: Benzodiazepine, Quinoxaline, Benzimidazole and Thiazole, Cyclization Reactions.

\section{Introduction}

Nitrogen containing heterocycles are frequently found in privileged structures (pharmacophores) but their incorporation sometimes possess special problems (multi step sequence, lack of generality, preparation from cyclic precursors,etc); thus, only a limited number of strategies have been successfully applied in the synthesis of heterocyclic scaffolds. The development of new, rapid and clean synthetic routes toward focused libraries of such compounds is therefore of great importance to both medicinal and synthetic chemists.Consequently,the design and development of procedures for the generation of new heterocycles receive growing interest.The benzimidazole ring is of a crucial pharmacophore in drug discovery. Benzimidazoles show different biological activities, such as anticancer, antimicrobial,or anthelmintic activities ${ }^{1}$.Benzimdazole derivatives are a unique broad-spectrum class of antirhino/enteroviral agents. Benzimidazoles exhibit cytomegalovirus $(\mathrm{HCMV})^{2}$.A number of synthetic methods have beendeveloped in recent years to uncover a variety of new reagents for the synthesis of benzimidazole derivatives
Benzimidazoles can be synthesized by a number of methods, usually involving formation of the N-C-N unit as the key step. One of the formally utilized general routs to benzimidazoles involves the reaction of aldehydes and ketones with $o$-phenylenediamine ${ }^{3}$. Although there are several routs leading to 2substituted benzimidazoles, a typical procedure involves heating $o$-phenylenediamine with a substituted carboxylic acid in the presence of a mineral acid ${ }^{4}$.

Brown rot, caused by the fungal Monilina fructicola(G.Wint.).Chemical control of brown rout is an important strategy for the management of this disease. The Benzimidazole fungicides like Benomyl ,Carbendazine,Chlorofenazole,Thiophanat, etc. have been widely used for controlling the disease ${ }^{5}$.

Benzodiazepines are a family of prescription drugs that are used mainly to relieve anxiety and to help people to sleep.These are sedative drugs, which reduce activity in certain parts of your brain,resulting in a calming effect Xanax (alprazolam), Rivotril (clonazepam), Valium (diazepam), Dalmane (flurazepam),
*Department of Chemistry, College of Science, Al-Nahrain University,Baghdad, Iraq
Ativan(lorazepam),Restoril (temazepam),Halcion (triazolam), etc, are examples of benzodiazepine drugs 6 . 
Other uses of benzodiazepines include :inducing sedation for sur-gical and other medicinal procedures treatment of alco- hol withdrawal controlling seizures relaxation of skeletal muscles, such as the back and neck ${ }^{7}$.

Among the various classes of heterocyclic compounds, quinoxaline form an important component of pharmacologically active compounds. Quinoxaline ring is a part of various antibiotics such as Echinomycine, Levomycine and Actnomycine that are known to inhibit the growth of Gram positive bacteria and are active against varioustrans plantable tumors ${ }^{8}$. Quinoxalinediones and their derivatives are important members of heterocyclic compounds that are widely applied in many fields, as curatorial intermediates, bactericides and inseticides ${ }^{9}$.One-pot efficient synthesis of quinoxaline-dione derivatives may permit the development of novel therapies for the treatment of epilepsy, pain and other neurodegenerative disorders ${ }^{10}$.

Because of its synthetic utility and broad rang of pharmacological activities, the thiazole nucleus is an important heterocyclic ring.Some thiazole derivatives with different pharmacological effects,including anti HIV, antihistaminic, antiulcer,cardiotonic, antihypertensive and neuroleptic,are in clinical use ${ }^{11}$. In order to obtain more effective chemotherapeutic agents, a variety of reports have been presented on the synthesis and biological evolution of new thiazole derivatives ${ }^{12}$.

\section{Experimental \\ General}

Melting points were determined on Gallen Kamp melting point apparatus and were uncorrected. The IR spectra of the compounds were recorded on Shimadzu FTIR8300 spectrometer as $\mathrm{KBr}$ disc; results are given in $\mathrm{cm}^{-1} .{ }^{1} \mathrm{H}-\mathrm{NMR}$ and ${ }^{13} \mathrm{C}$-NMR spectra were recorded at 300.131 and $75.47 \mathrm{MHz}$, respectively,in DMSO- $\mathrm{d}_{6}$ for all compo- unds on a Bruker AMX-400 NMR spectro- meter. The chemical shifts are reported in part per million (ppm) downfield from internal tetramethylsilane (TMS) (chemical shift in $\delta$ values).Thin layer chromatography was carried out using Fertigfollen precoated sheets type Polygram SilG, the plates were developed with iodine vapour. ${ }^{1} \mathrm{H}$-and ${ }^{13} \mathrm{C}$-NMR were made at Medicinal and Health Analytical Center, Peking University, China.

Synthesis of 4-methyl-1,3-dihydro-2H-1,5benzodiazepin -2-one (2)

A mixture of $o$-phenylenediamine(1) $(0.015 \mathrm{~mol})$ and $(0.015 \mathrm{~mol})$ of ethylacetoa cetate, in $20 \mathrm{ml}$ abs. ethanol was reflux for $24 \mathrm{~h}$. The excess solvent was removed under reduced pressure, the reaction mixture was cooled and the formed precipitate was filtered off and recrystallized from ethanol to give the desired products. M.P. $158-159 \mathrm{C}^{\circ}$, Yield $85 \%$.

\section{Synthesis of 1H-1,5-benzo diazepine-2,4(3H,5H)-dione (3)}

The same procedure as for the synthesis of compound 2 but use malonic acid instead of ethylacetoacetate.M.P.187-189C ${ }^{\circ}$, Yield 70\%.

Synthesis of 2,4-dimethyl-3H-1,5-benzodia zepine (4)

The same procedure as for the synthesis of compound 2 but use acetylactone instead of ethylacetoacetate.M.P.115-117C ${ }^{\circ}$, Yield 75\%.

Synthesis of 3,4-dihydroquinoxalin-2amine (5)

A solution of $(0.01 \mathrm{~mol})$ of compound 1 and $(0.01 \mathrm{~mol})$ of potassium hydroxide in $15 \mathrm{ml}$ abs. ethanol was added to $(0.01 \mathrm{~mol})$ of chloroacetamide.The reaction mixture was heated under reflux for $24 \mathrm{~h}$, and then the solid that formed was separated by filtration and recrystallized from chloroform to give the final products. M.P. $198-200 C^{\circ}$, Yield 60\%.

\section{Synthesis of 3,4-dihydroquinoxalin-2(1H)-} one (6)

A solution of $(0.01 \mathrm{~mol})$ of compound 1 and $(0.01 \mathrm{~mol})$ of potassium hydroxide in $15 \mathrm{ml}$ abs. Ethanol was added to $(0.01 \mathrm{~mol})$ of chloroacetic acid. The reaction mixture was heated under reflux for $24 \mathrm{~h}$, and then the solid that formed was separated by filtration and recrystallized from chloroform to give the final products.M.P. $170-172 \mathrm{C}^{\circ}$, Yield $70 \%$.

Synthesis of 3 - (4 - bromophenyl ) -1, 2 dihydroquinoxaline (7)

A mixture of compound $1(0.015 \mathrm{~mol})$ and $p$-bromophenacyl bromide $(0.015 \mathrm{~mol})$ in $25 \mathrm{ml}$ abs. ethanol was refluxed for $24 \mathrm{~h}$; then the solvent was reduced to one third its volume under reduced pressure and then cooled. The solid that separated was recrys- 
tallized from dichloromethane. M.P. $78-80 \mathrm{C}^{\circ}$, Yield $80 \%$.

Synthesis of 1,4-dihydroquinoxaline-2,3dione $(8)^{10}$

A mixture of oxalic acid dihydrate $(0.012 \mathrm{~mol})$ and $o$-phenylenediamine $(0.012$ mol) was thoroughly ground with a pestle in a mortar at R.T. In an open atmosphere until the mixture turned into a melt. The mixture continued to be ground occasionally for $1 / 2 \mathrm{~h}$. Then the melt was crystallized from water/ethanol (1:1) mixture to get the pure product. M.P.155 $-157 \mathrm{C}^{\circ}$, Yield $80 \%$.

\section{Synthesis 2-phenyl-1H-benzimidazole (9)}

To $(0.01 \mathrm{~mol})$ of compound $\mathbf{1}, \mathrm{a}$ mixture of $(0.01 \mathrm{~mol})$ of benzoic acid with few drops of conc. hydrochloric acid in $15 \mathrm{ml}$ abs. ethanol was added. Then the reaction mixture was heated under reflux for $15 \mathrm{~h}$. The crude product was isolated by filtration and recrystallized from acetone. M.P.210-212C ${ }^{\circ}$, Yield $65 \%$.

Synthesis of 2-(1,3-benzodioxol-5-yl)-2,3dihydro-1 $H$-benzimidazole (10)

A mixture of compound $\mathbf{1}(0.012 \mathrm{~mol})$, $25 \mathrm{ml}$ abs. ethanol and piperonal $(0.012 \mathrm{~mol})$ was heated under reflux for $24 \mathrm{~h}$. The reaction mixture was filtered off and recrystallized from chloroform. M.P. 230-232C $\mathrm{C}^{\circ}$,Yield $75 \%$.

\section{Synthesis of 1 , 3-dihydrospiro [benzim} idazol -2,1'-cyclohexane] (11)

A mixture of $(0.015 \mathrm{~mol})$ of compound 1 and $(0.015 \mathrm{~mol})$ of cyclohexanone in $20 \mathrm{ml}$ glacial acetic acid was heated under reflux for $24 \mathrm{~h}$, and then the mixture was filtered off to obtain the desired product. M.P. 220-222C ${ }^{\circ}$, Yield $60 \%$.

\section{Synthesis of 1H-benzimidazole-2-thiol (12)}

$o$-Phenylenediamine $(0.01 \mathrm{~mol})(\mathbf{1})$ and $(0.02 \mathrm{~mol})$ of $\mathrm{CS}_{2}$ was mixed together in $20 \mathrm{ml}$ abs. ethanol. The reaction mixture was refluxed for $18 \mathrm{~h}$. The crude product was obtained by filtration, washed with water and recrystallized from benzene. M.P. 90-92 $\mathrm{C}^{\circ}$, Yield $70 \%$.

Synthesis of $[1,3]$ thiazolo [ 3,2 - a] benzim idazol-3(2H)-one (13)

To a warmed sodium hydroxide solution prepared by dissolving of sodium hydroxide $(0.01 \mathrm{~mol})$ and $(0.01 \mathrm{~mol})$ of compound 12 in $15 \mathrm{ml}$ abs. ethanol, $(0.01 \mathrm{~mol})$ of chloroacetic acid was added. The reaction mixture was refluxed for 24h.The solid precipitate was formed after the solvent was reduced to one third its volume under reduced pressure.Crude product was obtained by filtration and recrystallized from benzene. M.P. $112-114 C^{\circ}$, Yield $80 \%$.

\section{Results and Discussion}

In the current study, o-phenelenediamine (1) was chosen as starting material. One of our aims was to use the two nucleophilic center of this material in synthesis an interesting heterocyclic compounds. One of the two amino groups will be reacting in a normal manner and an intermolecular attack by the other amino group at ortho position was suggested to take place. In the first part of these synthetic procedures, compounds 2-4 were obtained from the reaction of compound 1 with ethylacetoacetate, malonic acid and acetyl acetone, respectively (Scheme I). Their structures were confirmed by FT-IR, ${ }^{1} \mathrm{H}-\mathrm{NMR}$ and ${ }^{13} \mathrm{C}-\mathrm{NMR}$ spectral data.

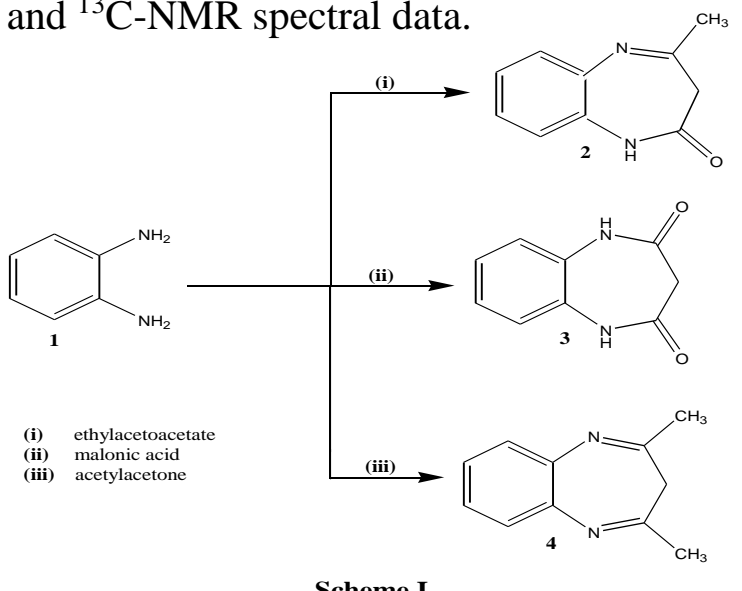

The mechanism of the reaction for the synthesis of compounds 2-4 is outlined below in
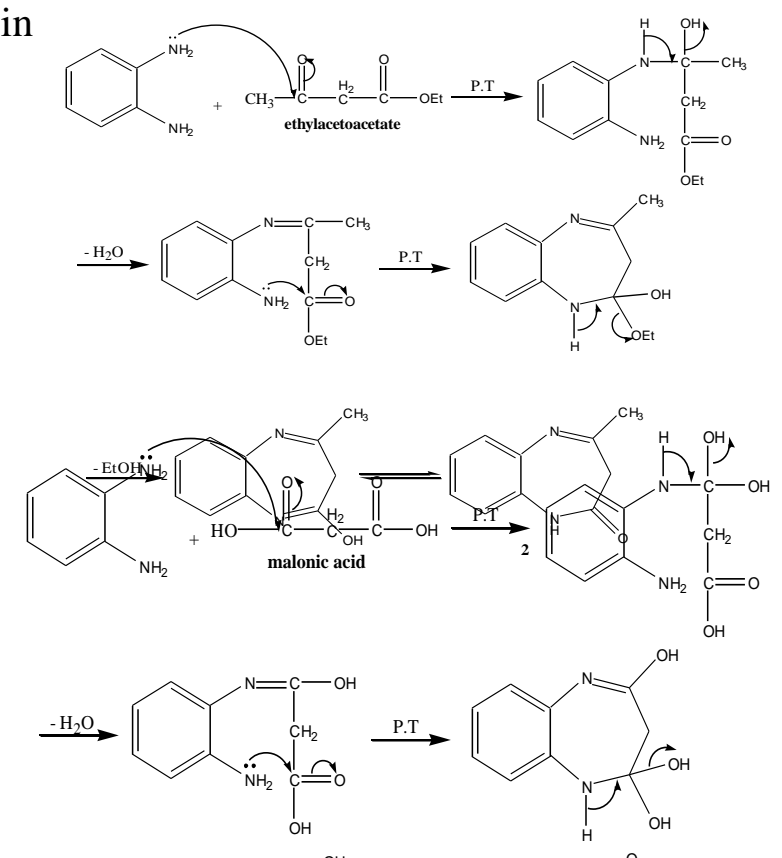


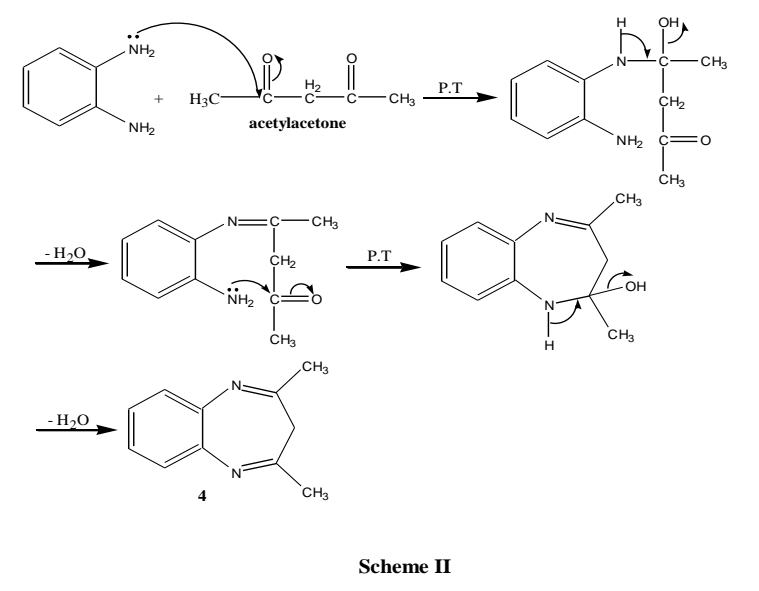

The IR spectra of compounds 4-methyl-1,3dihydro-2H-1,5-benzodiazepin -2-one (2) and 1H-1,5-Benzodiazepine-2,4 $(3 \mathrm{H}, 5 \mathrm{H})$-dione (3) (Fig. 1) showed characteristic bands at 3400$3300,2900-2800$ and 1650-1700 due to stretching vibrations of $\mathrm{OH}, \mathrm{CH}$ aliphatic and $\mathrm{C}=\mathrm{O}$ groups, respectively. From this we can say that these two compounds can exist in two tautomeric forms keto and enol forms. The signals corresponding to aliphatic protons, $\mathrm{NH}$ and $\mathrm{OH}$ protons were recorded at $1.14\left(\mathrm{~s}, 3 \mathrm{H}, \mathrm{CH}_{3}\right), 8.32(\mathrm{~s}, 1 \mathrm{H}, \mathrm{NH})\left(\mathrm{D}_{2} \mathrm{Oexcha}\right.$ nge), $9.21(\mathrm{~s}, 1 \mathrm{H}, \mathrm{OH}) \quad\left(\mathrm{D}_{2} \mathrm{O}\right.$ exchange $)$ for compound 2 and at $2.10\left(\mathrm{~s}, 2 \mathrm{H}, \mathrm{CH}_{2}\right), 8.44$ and 8.71(s, $1 \mathrm{H}, \mathrm{NH})\left(\mathrm{D}_{2} \mathrm{O}\right.$ exchange $), 9.35(\mathrm{~s}, 1 \mathrm{H}$, $\mathrm{OH})\left(\mathrm{D}_{2} \mathrm{O}\right.$ exchange), for compound 3 , in ${ }^{1} \mathrm{H}-$ NMR spectra. The $\mathrm{C}=\mathrm{O}$ signal appear at 170.1 and 164.7,168. 3 for compounds 2 and 3, respectively,in ${ }^{13} \mathrm{C}-\mathrm{NMR}$ analysis. Compound 4 displayed bands in its IR spectrum at 2900 and 1610 belonging to $\mathrm{CH}$ aliphatic and $\mathrm{C}=\mathrm{N}$ stretching vibrations. ${ }^{1} \mathrm{H}-\mathrm{NMR}$ spectrum showed signals at $1.21(\mathrm{~s}, 6 \mathrm{H}$, $\left.2 \mathrm{CH}_{3}\right)$ and $6.89-7.56(\mathrm{~m}, 4 \mathrm{H}$, aromatic protons), these two groups appeared at 14.6, 15.7 $\left(2 \mathrm{C}, \mathrm{CH}_{3}\right)$, and 132.0-136.4(6C, aromatic carbons) in the ${ }^{13} \mathrm{C}$-NMR spectrum.In the second step of this study, quinoxaline derivatives 5-8 were obtained by the reaction of compound 1 with chloroacetamide, chloroacetic acid, $p$-bromophenacyl bromide and oxalica cid dihydrate,respectively,(Scheme III).

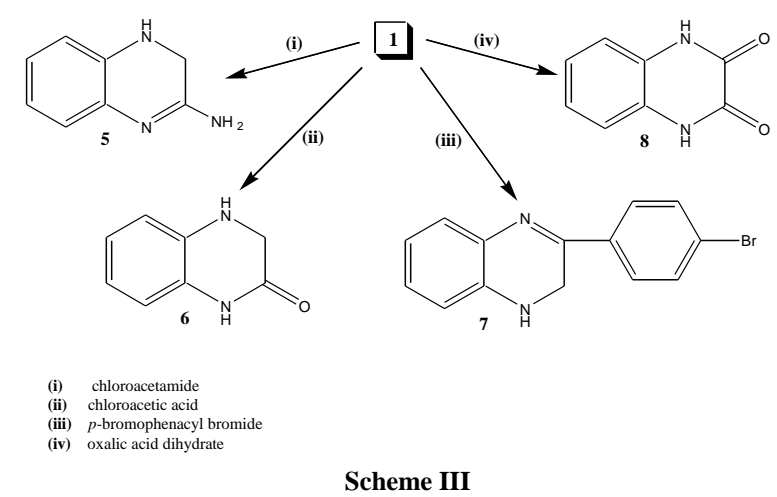

In the IR spectra of compounds 5-8, Fig. 2 show FT-IR spectrum of compound $\mathbf{8}$, the stretching multiple bands derived from $-\mathrm{NH}_{2}$ group of $o$-phenylenediamine were absent. In addition, signal derived from $\mathrm{C}=\mathrm{O}$ was observed, at 168.7 and $170.7,172.4$ in the ${ }^{13} \mathrm{C}-\mathrm{NMR}$ spectra of compounds $\mathbf{6}$ and $\mathbf{8}$, respectively. Beside this, the signal corresponding to $-\mathrm{NH}$ group was recorded at the range 8.21-8.55 in the ${ }^{1} \mathrm{H}-\mathrm{NMR}$ spectra of these compounds which were disappear with $\mathrm{D}_{2} \mathrm{O}$ exchange. Furthermore, ${ }^{1} \mathrm{H}-\mathrm{NMR}$ spectra of compounds $\mathbf{5}$ and $\mathbf{7}$ showed signals at 8.71 which was integrated for two protons corresponding to $-\mathrm{NH}_{2}$ group of compound $\mathbf{5}$, this was disappeared with $\mathrm{D}_{2} \mathrm{O}$ exchange, while the structure of compound 7 was confirmed by a multiple signal at $6.81-7.44$ due to aromatic protons. In the last part of the synthesis reactions,compound $\mathbf{1}$ was treated with benzoic acid ,piperonal ,cyclohexanone and carbon disulfide ;

2 -phenyl-1H-benzimidazole (9) ,2-(1,3benzodioxol-5-yl)-2,3-dihydro- $1 H$-benzimi dazole(10),1,3-dihydrospiro[benzimidazol2,1'-cyclohexane](11) and 1H-benzimidazole2-thiol (12) were formed respectively. Then compound (12) was converting to $[1,3]$ thiazolo[3,2-a]benzimidazol $-3(2 \mathrm{H})$-one (13) by treating with chloroacetic acid in abs. ethanol (Scheme IV). 
The ${ }^{1} \mathrm{H}-\mathrm{NMR}$ spectra of compound 9 and 10 showed characteristic signals at 8.30$8.84(\mathrm{~s}, 1 \mathrm{H}, \mathrm{NH})$ which was further characterized by $\mathrm{D}_{2} \mathrm{O}$ exchange. Beside this, in the ${ }^{1} \mathrm{H}-\mathrm{NMR}$ spectrum of compound 11, there were a multiple signals at 1.80-2.05 belonging to $-\mathrm{CH}_{2}$ - group of cyclohexane ring. On the other hand, ${ }^{1} \mathrm{H}-\mathrm{NMR}$ spectrum of compound $\mathbf{1 2}$ showed signal at 5.51 due to $-\mathrm{SH}$ group which was disappear with $\mathrm{D}_{2} \mathrm{O}$. When compo- und $\mathbf{1 2}$ was converted to compound 13, signal of -SH group was disappear and a new signal at 2.25 was shown which represent $-\mathrm{CH}_{2}$ - group, in ${ }^{1} \mathrm{H}-\mathrm{NMR}$ spectrum. Furthermore, ${ }^{13} \mathrm{C}-\mathrm{NMR}$ spectra of compounds 9-13 give a good support for the IR and ${ }^{1} \mathrm{H}-\mathrm{NMR}$ data of these compounds. Table I summarize phy- sical properties of the synthesized compo- unds; Table II shoes characteristic spectral data of these compounds.

Table I: Physical properties of compounds 2-13

\begin{tabular}{|c|c|c|}
\hline $\begin{array}{c}\text { Compound } \\
\text { No. }\end{array}$ & $\mathbf{M . P} /{ }^{\circ} \mathbf{C}$ & \%Yield \\
\hline 2 & $158-159$ & 85 \\
\hline 3 & $187-189$ & 70 \\
\hline 4 & $115-117$ & 75 \\
\hline 5 & $198-200$ & 60 \\
\hline 6 & $170-172$ & 70 \\
\hline 7 & $78-80$ & 80 \\
\hline 8 & $55-157$ & 80 \\
\hline 9 & $210-212$ & 65 \\
\hline 10 & $230-232$ & 75 \\
\hline 11 & $220-222$ & 60 \\
\hline 12 & $90-92$ & 70 \\
\hline 13 & $112-114$ & 80 \\
\hline
\end{tabular}

Table II:spectral data of compounds 2-13

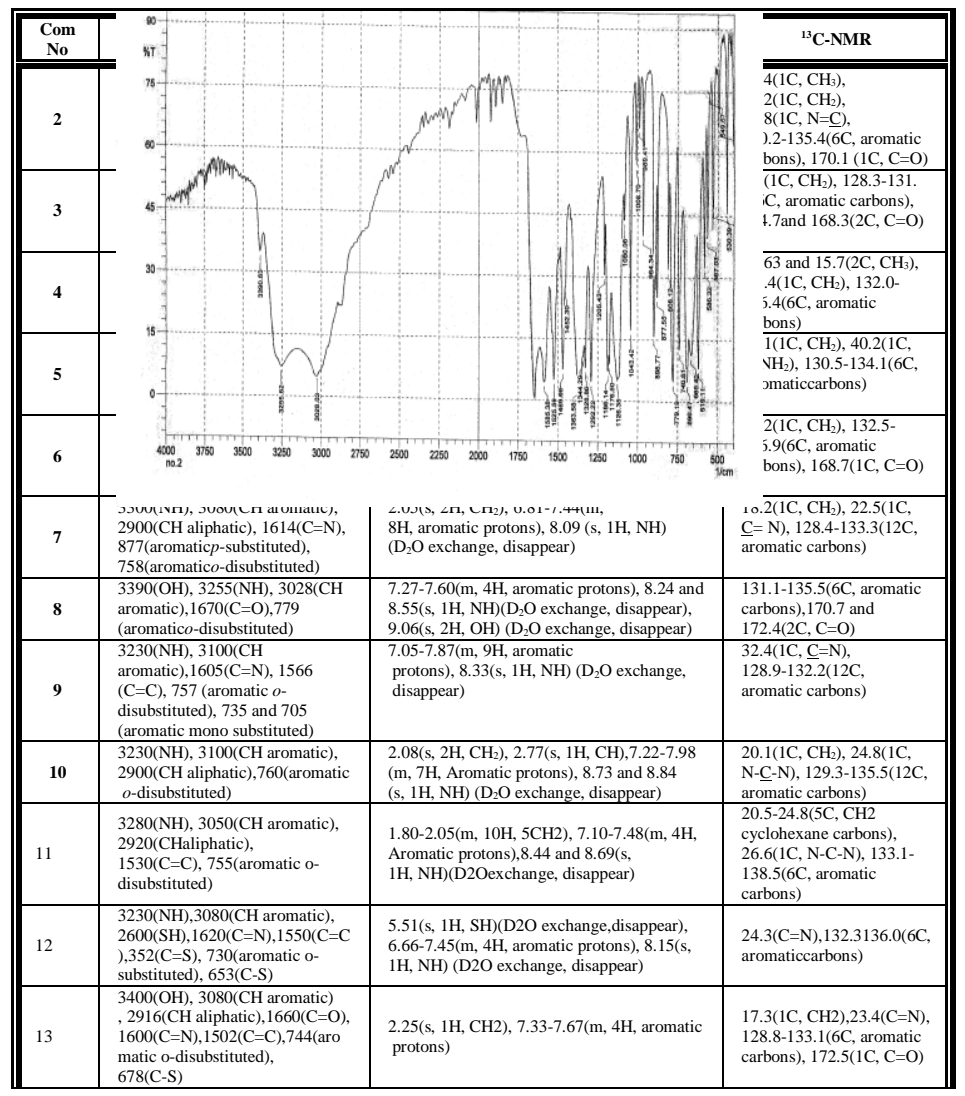

Fig. 1: FT-IR spectrum of compound 3

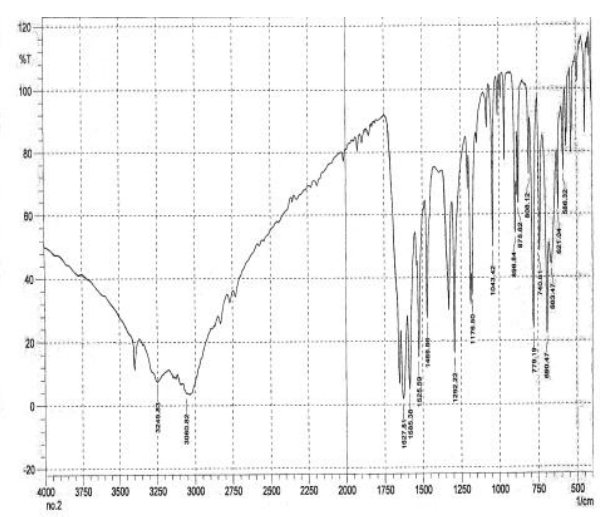

Fig. 2: FT-IR spectrum of compound 8 


\section{References}

1-Lu,J.,B.Yang and Y.Bai,2002.Microwave irradiation synthesis of 2-substituted benzim idazoles using PPA as a catalyst under solvent-free conditions.Synth. Commun. 32 (24): 3703-3709.

2-2.Tandon,V.K.and M.Kumar,2004. BF3Et 20 promoted one-pot expeditious and convenient synthesis of 2-substituted benzimidazoles and 3,1,5-benzoxadiaze-pines.Tetra hedron Lett. 45: 4185-4187.

3-Dege,N.,M.Şekerci,S.Servi,M.Dinçer and Ü.Demirbas,2006.Structure of1-(thiop-hen2-ylmethyl)-2-(thiophen-2-yl)-1H-benzimidazole.Turk.J.Chem. 30: 103-108.

4- 4.Rodriguez,M.L.,B.Benhamu,M.J.Morcillo and M.I.Martin,1999.Design and synthesis of new benzimidazole-arylpiperazine derivatives acting as mixed 5-HT1A 15-HT3ligands.J.Med.Chem.42:5020-5025.

5-Ma,Z.,M.A.Yoshimura and T.J.Michallides, 2003.Identification and Characterization of Benzimidazole Resistance in Monilinia fructicola from Stone Fruit Orchards in California. Applied and Environmental Microbiology.69(12):7145-7160.

6- Tomei,L.,S.Altamura,L.Bartholomew,A. Biroccio and G.Migliaccio ,2003.Mechanism of action and antiviral activity of benzimidazole-based allosteric inhibitors of the hepatitis C virus RNA-dependent RNA polymerase.J of Virology.77(24): 1322513231.

7-Elnima,E.,M.U.Zubair and A.A .Al-Bader ,1981.Antibacterial and antifungal activities of benzimidazole and benzoxazole derivatives.Antimicrobial Agents and Chemotherapy.19(1):29-32.

8- Bailly,C.,S.Echepare,F.Gago and M.Waring,1999.An efficient and facile synthesis of quinoxaline derivatives catalyzed by $\mathrm{KHSO}_{4}$ at room temperature.J.Anti- cancer Drug Des. 15:291-296.

9-Rahul,R.and B.Devanand,2006. $\mathrm{BF}_{3} . \mathrm{OEt}_{2}$ Promoted solvent-free synthesis of benzimidazole derivatives. Chinese Chemical Letters. 17: 453-456.

10-Thakuria,H.and G.Das,2006.One-potefficient green synthesis of 1,4-dihydroquinoxaline-2,3-dione derivatives.J.Chem.Sci. 118 (5): 425-428.

11-Kus,C.,2002.Synthesis of new substituted 6-(morpholin-4-yl)-1H-benzimidazole derivatives. Turk. J. Chem. 26:559-564.

12-Nakano,H.,T.Inoue,N.Kawasaki and T.Satoch,2000.Synthesis and biological activities of novel antiallergic agents with 5-lipoxygenase inhibiting action,Bioorganic and Medicinal Chemistry.8(2):373-380.

\section{تحضير وتثخيص مركبات حلقية غير متجانسة ملتحمة جديدة جديدة تحتوي على حلقات التيزئ

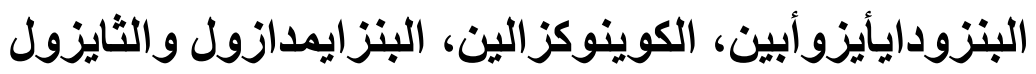 المدرس الاكتورة نادية عادل صالح" والمدرس المساعد حنان عبد اللطيف ابراهيم"}

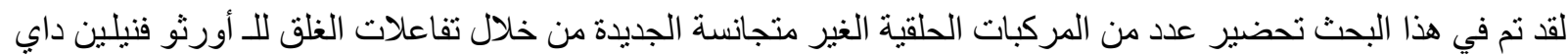

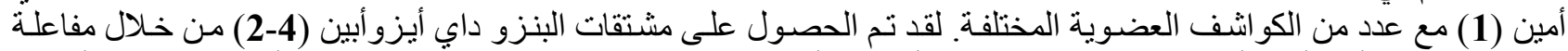

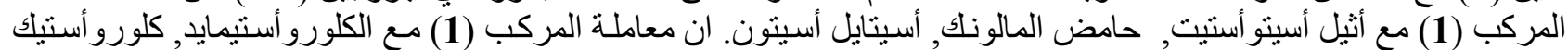

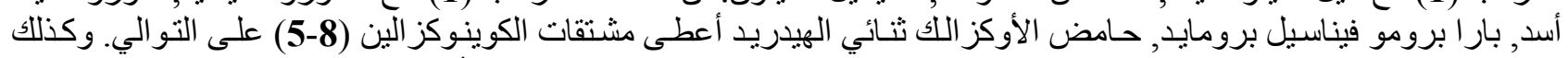

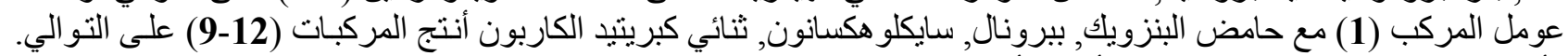

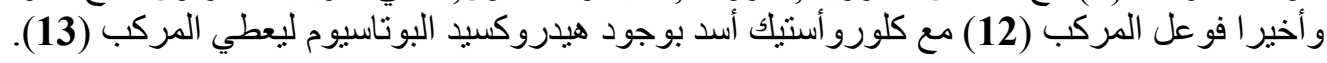

